\title{
AC 2010-1102: EVALUATION OF SUSTAINABLE ENGINEERING EDUCATION VIA SERVICE LEARNING AND COMMUNITY SERVICE EFFORTS
}

Mary McCormick, Tufts University

Kristina Lawyer, Michigan Technological University

Meredith Berlin, University of Colorado - Boulder

Chris Swan, Tufts University

Kurt Paterson, Michigan Technological University

Angela Bielefeldt, University of Colorado, Boulder

Jonathan Wiggins, University of Colorado, Boulder 


\title{
Evaluation of Sustainable Engineering Education via Service Learning and Community Service Efforts
}

\begin{abstract}
Sustainable engineering considers the potential environmental, health, economic, and social impacts in conceiving, developing, and constructing products or systems. Sustainable engineering technologies that emerge are designed to meet the current needs of a client or community and to endure anticipated future challenges. Sustainable engineering education is critical in moving towards the paradigm of a sustainable world. For students to discern the impact of engineering decisions on multiple levels requires a unique pedagogical approach; sustainable engineering education will enable them to implement holistic problem-solving methods and deliver sustainable solutions.
\end{abstract}

Although sustainable engineering programs are proliferating in engineering education, there is little supporting evidence regarding the quality of these learning experiences. One approach, sustainable engineering through service learning, appears to have pedagogical advantages, but has yet to be rigorously explored. This paper outlines an approach to evaluate if such an advantage exists. Our goal is to determine if (and how) service learning provides an appropriate method to instill sustainable engineering educational outcomes in engineering students. Service learning has been shown to enrich students' learning experiences and to be intrinsically motivational to engineering students. Consequently, we are evaluating the outcomes resulting from the explicit integration of sustainable engineering and service learning in engineering education. Sustainable engineering via service learning efforts, both curricular and extracurricular, are being practiced in civil and environmental engineering programs at many institutions. In this research detailed analyses will examine efforts at Tufts University, the University of Colorado-Boulder and Michigan Technological University. Our assessment will utilize existing qualitative and quantitative tools that measure knowledge and skills of, and attitudes towards, sustainable engineering concepts of participating engineering students. The research design will use mixed methods in a quasi-experimental, change-over-time approach. Match comparison control groups will consist of engineering students not involved in these service learning activities. From the collected data, we will establish a "Best Practices" framework to provide insight on the benefits, resources, and adoption of sustainable engineering via service learning.

\section{Background: Need for Sustainable Engineering}

Over the last few years, recognition of the need to shift the engineering education paradigm has escalated, fueled by a palpable sense of urgency. In response, professional organizations, industry executives, and faculty members have addressed the need for reform by prescribing the necessary skills and attributes with which engineers must be equipped to overcome future challenges $^{1,2}$. To identify the necessary skill sets and align them with accreditation criteria, the Accreditation Board of Engineering and Technology (ABET) sought guidance from a group of proactive industry leaders, all member of their Industry Advisory Council (IAC). The ABET 
IAC made it clear that sustainable development was becoming the dominant economic, environmental, and social issue of the $21^{\text {st }}$ century, and that "a fundamental change in engineering education was required to help the next generation of engineers design for sustainable development and long-range competitiveness" 3,4 . The IAC most notably placed emphasis on "teamwork and an interdisciplinary understanding of the societal, ecological, financial, national, and global impacts of engineering" 5 . These attributes, among others, formed the foundation for ABET Engineering Criteria 2000 (EC 2000) was geared towards students' abilities "to design...to meet desired needs within realistic constraints such as economic, environmental, social, political, ethical, health and safety, manufacturability, and sustainability...to understand the impact of engineering solutions in a global, economic, environmental, and societal context" 6 .

Many other organizations continually advocated this "educational reformation". The American Society of Civil Engineers' (ASCE) Code of Ethics requires civil engineers to "strive to comply with the principles of sustainable development in the performance of their professional duties ... [including] global leadership in the promotion of responsible, economically sound, and environmentally sustainable solutions that enhance the quality of life, protect and efficiently use natural resources" 7 . Concurrently, the National Academy of Engineers (NAE) ${ }^{1,8}$ created the Technology and Sustainable Development program, aimed at illuminating the relationship between ecology, economic growth, and the environment. In 1994, the American Society for Engineering Education (ASEE) issued a statement recommending that "Engineering students should learn about sustainable development and sustainability in the general education component of the curriculum as they are preparing for the major design experience" 9,10 . The basis for these calls for "reformation" can be traced to Our Common Future, also known as the Brundtland Report, issued by the United Nations World Commission on Environment and Development (WCED) in 1987. The Brundtland Report alerted the world to the urgency of making progress towards economic development that could be sustained without depleting natural resources or harming the environment. The definition of sustainable development appearing in the Brundtland Report soon became ubiquitous. According to the WCED, sustainable development is "development that meets the needs of the present without compromising the ability of future generations to meet their own needs" 11 . Furthermore, the report identified the three pillars of sustainability as environment, economy, and society, signifying that together, they form a complex system of interdependent components.

The core of the new engineering education paradigm is the belief that the solutions to current and future problems must consider the human dimension and that technological solutions must consider the social, political, environmental, and economic dynamics of the systems on a global scale. The underlying theme in education reform must be preparation to address global problems in sustainable ways. To meet future challenges, educators need to shift engineering pedagogies to help students learn a more all-encompassing, human-centered, problem-solving approach. As a group of faculty from several universities stated, "A long-term goal of 21 st century engineering education is to enable practicing engineers to incorporate tenets of sustainability into all phases of their practice, so that "sustainable engineering" eventually equates with "good engineering"12. The key challenge in engineering curricula is not to completely revamp the current program, but to "imbue the education of engineering students with the contingent nature of engineering solutions" $"$. 


\section{Reform in Progress}

The complex nature of sustainable engineering and the novelty of each problem make it difficult for students to learn, especially in a classroom setting. While desirable, sustainable engineering concepts are not simple to learn or teach. As one faculty member observes, "While engineering sustainability has become an increasingly popular topic in engineering, few programs provide significant instruction in the subject, especially design for sustainability" ${ }^{2}$. Over the past few years, many universities have taken the initial steps towards incorporating sustainable engineering concepts into their curricula. The Benchmarking Sustainable Engineering Education Report (BSEE) identifies accredited engineering programs at U.S. institutions that are currently incorporating sustainability concepts into engineering curricula and the degree to which information and concepts from non-engineering disciplines are being employed (BSEE) ${ }^{12}$. The BSEE report highlights the fact that several different approaches to sustainable engineering currently coexist, sometimes in the same institution. Additionally, the BSEE report explains that some professors integrate sustainability into traditional course material by selecting relevant case studies or exercises, while others establish stand-alone "sustainable engineering" courses or use sustainable engineering modules within the framework of existing courses. Each method has its own strengths and drawbacks; however, there is little evidence regarding the quality of learning experiences $^{12}$.

\section{Research Objective}

Our research aims to explore the integration of sustainable engineering and engineering education via service learning. Using a mixed method research design, we are investigating whether sustainable engineering is more deeply learned through service learning activities, and whether service learning experience influences students' attitudes towards sustainability and perceptions of engineering. While the pedagogical advantages of service learning are recognized, it is unclear if this is an appropriate channel through which sustainable engineering can be learned. Our goal is to more rigorously explore if (and how) service learning provides an appropriate method to educate engineering students in the field of sustainable engineering.

\section{Rationale for Hypothesis:}

The service learning environment places students in a real-world setting, allowing them to experience the social, economic, and environmental aspects associated with sustainable design. A unique learning environment can be a very powerful pedagogical tool. Vest states "Although we cannot know exactly what they should be taught, we can focus on the environment in which they learn and the forces, ideas, inspirations, and empowering situations to which they are exposed" ${ }^{14}$. Service learning provides a rich learning environment with many positive pedagogical affordances. We base our rationale on the following three: learning from (and through) experience, learning within a (real-world) context, and learning collectively to advance social progress.

\section{Learning from and through experience}

We hypothesize that service learning provides an effective means through which sustainable 
engineering can be learned. Rooted in learning theory, this hypothesis is strongly supported by the potential benefits of experiential learning ${ }^{15,16}$. Service learning is described as "a form of experiential education in which students engage in activities that address human and community needs together with structured opportunities intentionally designed to promote student learning and development" ${ }^{17}$. An experiential learning framework engenders knowledge creation through the "transformation of experience" 18 . Immersed in a community, students become aware of the technical and non-technical impacts of their designs first-hand. They are exposed to the implicit complications - on economic, societal, and environmental levels- and may need to adjust their designs to achieve the proper balance. The service learning design process naturally encourages a holistic problem-solving approach and potentially heightens student awareness of the non-technical aspects involved in engineering design. As one author posits, students who engage in service learning "may develop greater complexity in their thinking; ethical commitments regarding themselves, their lifestyles, and what they know and believe; movement toward higher levels of moral reasoning; and development and clarity about their faith and spirituality" 18 .

\section{Contextualized Design}

A major focus in reforming engineering education is to more fully integrate design into engineering curricula, without compromising the importance of analysis. Both design and analysis are essential; however, "Analysis deepens perspective. Design widens it," 19 . If engineering design widens students' perspectives, then sustainable engineering design may widen their perspectives enough to include the non-technical aspects of design. Coincidentally, the real world situations and constraints inherent to service learning have been shown to trigger a broadening of students' perspectives ${ }^{20}$.

The engineering design process is adapted according to the engineer's perception of the problem and the constraints. Engineering design is often described in terms of content and context, where content pertains to the elements of the design and context encompasses the environment in which the content is embedded ${ }^{19}$. Students typically learn engineering design as it applies to specific course material, focusing on and analyzing the technical aspects of design- the content. Sustainable engineering design requires students to address the environment (physical, social, economic, etc.) in which they are designing- the context. As Pappas suggests, "Understanding the far-reaching influence design has on the individual as well as on groups of people (communities, professional communities, geographic regions, cultures) is critical to instruction"2. When engineering design is nested in a sustainability-focused, service learning framework, students' perspectives instinctively widen to span across disciplines. There is a necessary, complex systems analysis ingrained within sustainable engineering design. As Moriarty describes, "The economics, ethics, and politics of engineering, coupled with environmental concerns, encompassed by and understood within a philosophical and historical framework- all this, bound up in a complex web of interactions, seems essential for a full discourse of the context of engineering design" 19 . A cross-disciplinary, systems approach to engineering has always existed in the context of the real world, where the "processes of technological development have been shaped by social, cultural, and political forces" ${ }^{13}$. Because engineering design cannot be disconnected from the non-technical influences, "the practice of engineering must become more consciously contextualized if sustainability is to be realized"13. 


\section{Advancing Collective Engineering Knowledge}

Collaboration is an integral component in the service learning model; students work with each other and with the community to enhance the community's quality of life. In working together towards a common goal, students often form a "knowledge-building culture," in which they "see themselves and their work as part of the civilization wide effort to advance knowledge frontiers"

21. Recognizing the impact engineers can have on the world has been shown to increase intrinsic motivation to continue learning and to collectively improve ideas ${ }^{21}$. Accordingly, learning theorists have conjectured, "the driving force is not so much the individual interests of (students) as their desire to connect with what is most dynamic and meaningful in the surrounding society" 21. Instead of learning on an individual basis to achieve a high test grade, service learning provides opportunities for students to learn collaboratively in order to solve societal, economic, and environmental problems. As students' intrinsic motivation is "fueled by an internal sense of volition, freedom, and an inherent interest in and valuing of the activity," they choose to engage in learning, thereby learning autonomously ${ }^{22,23}$. Thus, the natural and valuable connection to sustainability engineering manifests itself within the service learning experience; students become an integral component in sustaining the advancement of engineering knowledge.

\section{Assessment Methodology}

Most engineering students are aware of the need for sustainable development; however, the depth to which they understand sustainable engineering design is unclear. The objective of this research is to measure whether students who have service learning experience have a deeper understanding of sustainable engineering than their counterparts who do not have service learning experience. The research design is comprised of three evaluations: sustainable engineering design, self-efficacy towards sustainable engineering, and epistemological beliefs towards general engineering. Each evaluation will be performed on engineering students at three different institutions which employ varying types of service learning programs; Tufts University, Michigan Technological University, and University of Colorado-Boulder. Students enrolled in the Civil and Environmental Engineering Senior Design/Capstone classes at all three schools will be asked to participate. Before beginning the evaluation, students will be asked to briefly describe their service learning experience; those with service learning experience will be the sample group, while those without service learning experience will be the control group. By diversifying the sample and type of service learning program, we hope to establish reliability and validity of assessment instrumentations. All instrumentation has been approved by the Institutional Review Board for each institution, and consent will be obtained from all subjects. The research program is scheduled to occur during the Spring 2010 term at the aforementioned institutions. The following are brief descriptions of the instrumentation, constructs, and implementation plan.

\section{Sustainable Engineering Design}

\section{Instrumentation:}

The sustainability engineering challenge questions are open-ended, reality-based questions designed to neither encourage nor discourage incorporation of economic, societal, and environmental aspects into solutions. 
The rubrics are designed to minimize the biases inherent to qualitative research. Answers will be scored according to how in-depth they are with respect to economic, societal, and environmental aspects and whether the interdependency among these aspects is evidenced. The rubric scheme will be adjusted to capture a range of answers after coding phrases.

We will verify inter-rater reliability and parallel-forms reliability during scoring and data analysis. Additionally, we will ensure content validity, which will involve an evaluation of the extent to which a measurement represents all facets of a specific domain ${ }^{24,25}$. In this case, the students' answers (measurement) will be compared to all facets of sustainable engineering (specific domain). As a guide for content measurement, Figure 1 shows a conceptual model of the information flows that occur when sustainability is integrated into engineering design (originally created by Mihelcic ${ }^{26}$, and adapted by the authors of BSEE ${ }^{12}$ ). Scores will be based on whether students recognize the existence of, see the link between, or realize the interdependence among the economic, societal, and environmental aspects.

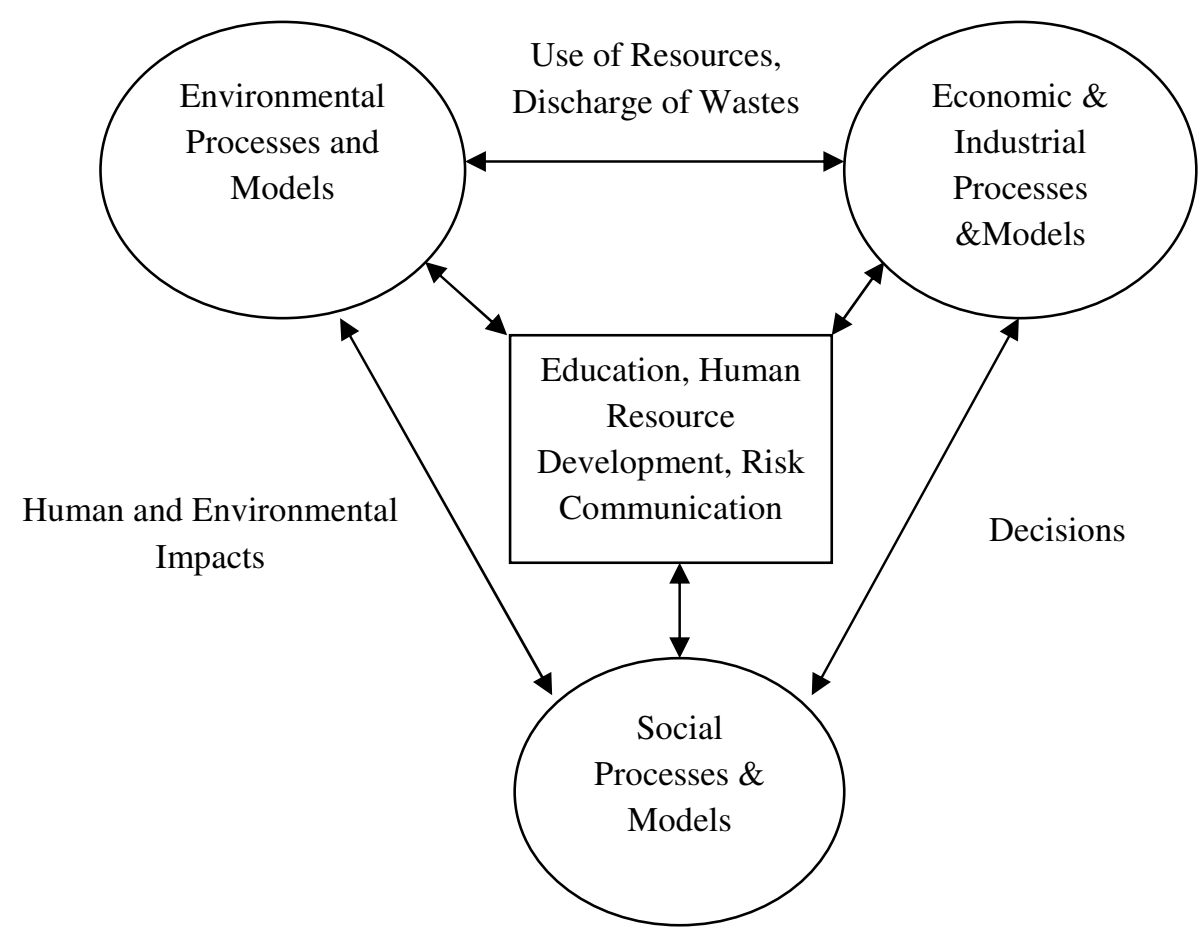

Figure 1: Conceptual Model of information flows that occur when sustainability is integrated into engineering design (from Mihelcic et al 2003) ${ }^{12,26}$.

\section{Data Collection:}

Students will self-select one of two sustainability challenge questions on the first day and again on the last day of their design experiences (a "pre- and post- evaluation" process). Prior to answering, students will complete a brief demographic and experience-related set of questions, one of which pertains to previous service learning and/or design experience. Students will be constrained to a single handwritten page for their responses, and will be given 30 to 45 minutes to complete the evaluation. The challenge questions are located in Appendix A. 


\section{Sustainable Engineering Self-Efficacy}

\section{Instrumentation:}

Self efficacy is the belief in ${ }^{27-29}$ "one's capabilities to organize and execute the courses of action required to manage prospective situations." To perpetuate sustainable engineering opportunities within the engineering curricula, students must be motivated. Since self-efficacy influences the 28, 29 "choices (students) make, the effort (students) put forth, how long (students) persist, and how (students) feel," higher sustainable engineering self efficacy could lead to higher student involvement and engagement. Furthermore, engineering students may see themselves as more capable of contributing and developing a sustainable environment. As stated by Bandura ${ }^{29}$,

"Those who have a firm belief in their efficacy, through ingenuity and perseverance, figure out ways of exercising some control, even in environments containing limited opportunities and many constraints...They set themselves challenging goals and maintain strong commitment to them. They maintain a task-diagnostic focus that guides effective performance. They heighten and sustain their efforts in the face of failure."

Self efficacy is a context-specific assessment of one's competence to perform a specific task or a range of tasks in a given domain. Self-efficacy towards sustainable engineering takes into account how students perceive their abilities to practice sustainable engineering; more specifically, their perceived abilities to recognize the existence of, see the link between, or realize the interdependence among economic, societal, and environmental aspects of engineering design. The pilot instrument was designed to measure student confidence, motivation, expectancy for success, and anxiety towards sustainable engineering. Students' self-perceptions of abilities will be scored using a 0 to 10 Likert scale $(0=$ strongly disagree, $10=$ strongly agree), a format that has been found to be a stronger predictor of performance than the 5 -point interval Likert Scale ${ }^{30}$.

\section{Data Collection:}

Since the self efficacy instrument is in online survey, the link to the survey will be sent to students by email shortly after they complete the challenge questions. The instrument, consisting of four multi-component questions, is expected to take approximately 10 minutes to complete. To coincide with the challenge questions, the self efficacy instrument will be disseminated to the same sample of students at the end of the semester as part of the pre- and post- evaluation.

\section{Epistemological Beliefs}

\section{Instrumentation:}

Epistemological beliefs refer to the underlying assumptions students hold regarding the sources and development of knowledge; the nature of knowledge (certainty of knowledge \& simplicity of knowledge), and the nature of knowing (source of knowledge \& justification of knowledge) ${ }^{31}$. Students' epistemological beliefs have been found to influence cognitive engagement, academic 
achievement, and motivation to learn ${ }^{32,33}$. Because epistemological beliefs often reflect personal experiences $^{31}$, our study will compare engineering epistemological beliefs of students who have participated in service learning projects to the beliefs of those who have not. Our aim is to gain insight as to how students perceive engineering design and whether service learning experience may affect their perceptions.

Since epistemological beliefs are students' subjective theories that describe the structure and acquisition of knowledge, the instrument must be sensitive to leading biases. Our pilot instrument is designed to measure students' perceptions of engineering design (certainty of knowledge or sources of knowledge). Students will again answer according to a 0 to 10 Likert scale $(0=$ strongly disagree, $10=$ strongly agree $)$.

\section{Data Collection:}

The epistemological beliefs instrument is attached to the self-efficacy instrument. It will also be disseminated to the same sample of students by the email link, and is expected to take approximately 5 minutes to complete. Participating students will be asked to complete the epistemological beliefs survey at the beginning and end of the semester as part of the pre- and post- evaluation format.

\section{Conclusion}

Engineers are the "implementing interface between science decision making bodies and society," 34 and, as such, need to "engage more actively in political, economic, technical, and social discussions and processes to help set a new direction for the world and its development" 35 . Is the engineering education paradigm preparing them to overcome these future challenges? How can educators broaden students' perspectives so they may naturally engage in holistic problemsolving approaches? Is there a way to imbue engineering education with a more human-centered approach to engineering? The need for sustainable engineering education within engineering curriculum is evident; the challenge is finding an effective pedagogical approach. This research will explore whether service learning projects provide a means through which sustainable engineering can be learned. Our exploration consists of three complementary measures, from which we hope to gain insight into students' abilities to understand and practice sustainable engineering; their attitudes (motivation, confidence, anxiety) towards sustainable engineering; and the nature of their engineering knowledge.

We plan to collect data in the beginning and end of the Spring 2010 semester. These pre- and post-experience evaluations will help us ascertain whether students' sustainable engineering design abilities, self-efficacy towards sustainable engineering, and engineering epistemological beliefs changed during the semester. After verifying reliability and validity of instrumentation, we will use the comparative data in conjunction with each individual's service learning and/or sustainable design experiences to make inferences regarding the pedagogical advantages and/or disadvantages of service learning as a means of practicing, learning, and understanding the process of sustainable engineering.

Further, we plan to use our findings to develop a "best practices" model for sustainable engineering via service learning. The formative implementation and evaluations efforts of the research will serve as a basis for the development, execution, and refinement of the model(s). 
Lastly, we will produce a final report to summarize our findings as well as create an internet site for interested parties to contribute to, view, or edit.

\section{Bibliography}

1. National Academy of Engineering. (2005). Educating the engineer of 2020: Adapting engineering education to the new century. Washington, DC: National Academy Press.

2. Pappas, E. \& R. Kander. (2008). "Sustainable Societies: The Sustainable Engineering Design Curriculum at James Madison University," Proceedings of the 2008 ASEE Annual Conference, Pittsburgh, PA.

3. Splitt, Frank G. (2002). Engineering Education Reform: A Trilogy. Published by the International Engineering Consortium.

4. Brewer, Garry D. (1992). "Business and the Environment: A Time for Creative and Constructive Coexistence," The Twenty-fifth Annual William K. McInally Memorial Lecture, School of Business of Administration, The University of Michigan, March 31, 1992.

5. Hatch, Henry J. (1992). "Accepting the Challenge of Sustainable Development," The Bridge, National Academy of Engineering, Washington, DC, Spring 1992.

6. Criteria for Accrediting Engineering Programs, Baltimore, Maryland: Accreditation Board for Engineering and Technology (ABET), Dec 26, 2000. www.abet.org (ABET re: Engineering Criteria 2000: Criterion 3 Programs Outcomes Assessment)

7. American Society of Civil Engineers. 1996. "Code of Ethics." http://www.asce.org/inside/codeofethics.cfm

8. Frosch, Robert A., et al, (1999). The Bridge, National Academy of Engineering, Vol. 29, No.1, Spring 1999.

9. American Society for Engineering Education (ASEE). 1994. "Report of the Committee on Evaluation of Engineering Education," (Grinter Report), reprinted in Journal of Engineering Education, Jan.: 7494.www.asee.org

10. Bosscher, P., J. Russel, W. Stouffer. (2005). "The Sustainable Classroom: Teaching Sustainability to Tomorrow's Engineers." Proceedings of the 2005 ASEE Annual Conference.

11. World Commission on Environment and Development. 1987. Our Common Future, Bruntland Report. Oxford: Oxford University Press, 1987 p. 43.

12. Allen, D., B. Allenby, M. Bridges, J. Crittenden, C. Davidson, C. Hendrickson, S. Matthews, C. Murphy, \& D. Pijawka. (2008). "Benchmarking Sustainable Engineering Education: Final Report." EPA Grant X383235101-0, December, 2008.

13. Barke, R. (2000). "Sustainable Technology: Development and Challenges to Engineering Education." Proceedings of the 2000 ASEE Annual Conference, St. Louis, Missouri.

14. Vest, Charles M. (2008). "Context and Challenge for Twenty-First Century Engineering Education". Journal of Engineering Education, July, 2008. p 235-240.

15. Eyler, J. \& Giles, D. E., Jr. (1999). Where's the learning in service-learning? San Francisco: Jossey-Bass.

16. Bringle, R. G., \& Hatcher, J. A. (2000). Successful service-learning programs: New models of excellence in higher education. Journal of Higher Education, 71(4), 504-507.

17. Jacoby, Barbara \& Associates (1996). Service learning in Higher Education. San Francisco. CA: JosseyBoss

18. Kolb, D. A. (1984). Experiential Learning: Experience as the source of learning and development. Englewood Cliffs, N.J: Prentice-Hall.

19. Moriarty, G. (1994). "Engineering Design: Content and Context," Journal of Engineering Education, April, 1994, p. 135-140.

20. McCormick, M., C. Swan, D. Matson. (2008). "Reading between the Lines: Evaluating Self-Assessments of Skills Acquired during an International Service learning Project." Proceedings of 2008 ASEE Annual Conference. Pittsburgh, PA.

21. Scardamalia, M., \& C. Bereiter. (2006). "Knowledge Building: Theory, pedagogy, and technology." In K. Sawyer (Ed.), Cambridge Handbook of the Learning Sciences (pp 97-118). New York: Cambridge University Press. 
22. Vanasupa, L., J. Stolk, R. Herter. (2009). "The Four-Domain Development Diagram: A Guide for Holistic Design of Effective Learning Experiences for the Twenty-first Century Engineer." Journal of Engineering Education. January 2009. p 67-81.

23. Deci, E.L., \& R.M. Ryan. (1985). Intrinsic motivation and self determination in human behavior. New York: Plenum.

24. Carminer, E.G. and R.A.Zeller.(1979). Reliability and validity assessment. 1979. Thousand Oaks, CA: Sage Publications.

25. Messick, S. (1989). "Validity in Educational Measurement," R.L. Linn, Editor. The American Council on Education and National Council on Measurement in Education: Washington, DC. pg 13-103.

26. Mihelcic, J.R. et al. (2003). "Sustainability Science and Engineering: The Emergence of a New Metadiscipline," Environmental Science Technology. 2003 (37), 5314-5324.

27. Bandura, A. (1986). Social foundations of thought and action: A social cognitive theory. Englewood Cliffs, NJ: Prentice-Hall.

28. Bandura, A. (Ed.). (1995). Self-efficacy in changing societies. New York: Cambridge University Press

29. Bandura, A. (1993). Perceived self-efficacy in cognitive development and functioning. Educational Psychologist, 28, 117-148.

30. (Pajares, F., Hartley, and G. Valiante, Response format in writing self-efficacy assessment: Greater discrimination increases prediction. Measurement and Evaluation in Counseling and Development, 2001. 33: p. 214-221.

31. Evans, M., \& R.D. Ravert. "Student Epistemological Beliefs: An Added Dimension of Learner Analysis for the Design of Online Instructional Strategies." Work in progress.

32. DeBacker, T.K. \& H.M. Crowson. 2006. "Influences on cognitive engagement: Epistemological Beliefs and need for closure." British Journal of Educational Psychology 76 (3): 535-51.

33. Palmer, B., and R.M. Marra, "College Student Epistemological Perspectives across Knowledge Domains: A Proposed Grounded Theory," Higher Education, Vol. 47, 2004, pp. 311-335.

34. "The Role of Engineering in Sustainable Development." (1994). A Publication of the American Association of Engineering Societies and the World Engineering Partnership for Sustainable Development.

35. World Federation of Engineering Organizations. (1997). "The Engineer's Response to Sustainable Development." 


\section{Appendix A}

* Usersname (only used to link your survey to question answer)

First 2 letters of your first name+ First 2 letters of your last name +2 numbers of your birthday Ex: John Smith born January 05, $1980=$ josm05

\section{Demographics:}

1. Gender: Male Female

2. Race:

3. Age: $\quad 18-19 \quad 20-21 \quad 22-23 \quad 23+$

4. Name of current institution:

5. Major:

6. Year: Freshman Sophomore Junior Senior Grad Student

7. Please write brief description and number of years of involvement you have with the following types of programs:

Extracurricular service-learning program (EWB, EPICS, ESW, etc.)

Internship or Co-op 
Undergraduate Research

Engineering Design Class/Capstone

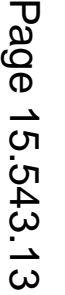




\section{Engineering Challenge Question}

Please answer one of the following questions. Please limit your answer to approximately one page.

Question A: As an engineering consultant, you were recently put on a team for a new project, and the client is your alma mater (the university you attended). The job involves providing recommendations on all aspects of new projects and on the potential renovation of existing facilities.

Note that the client (your university) is not exempt from the challenging economic times and is looking for ways to save money upfront and to reduce long term costs. What types of changes would you like to make to address these challenges? What will be the potential impact(s) of your recommendations? What are the foreseeable consequences of implementing your ideas?

Question B: A friend of yours (who is not an engineer) has recently returned from the Peace Corp work she was doing in a small village in Tanzania. She discussed the challenges the people there were facing and asked what you would do as an engineer to improve the quality of life. What products or services would you design or implement? What would be the potential impacts of these changes? What are the foreseeable challenges? 